\title{
VEINTE AÑOS DE LA REEC: IMPULSANDO UN NUEVO FUTURO
}

\section{Twenty years of REEC: promoting a new future}

\author{
Javier M. Valle López ${ }^{*}$ y Mª José García Ruiz ${ }^{* *}$
}

Hace 20 años se editó por vez primera la Revista Española de Educación Comparada (REEC). Gracias al impulso de la entonces recién renovada Sociedad Española de Educación Comparada (SEEC), nació como órgano de expresión científica de dicha sociedad por iniciativa de quien fue su primer Director, el profesor José Luis García Garrido.

Muchos han sido los cambios que se han producido en este tiempo en el contexto académico y, muy especialmente, en el ámbito de las publicaciones científicas.

La globalización, el uso generalizado de internet, la internacionalización de las universidades y la proliferación de revistas de carácter científico en las diferentes áreas del conocimiento (que supone una mayor competencia entre ellas), son sólo algunos de los factores que enmarcan esos cambios. Todos ellos han supuesto una creciente complejidad en la edición, gestión y difusión de este tipo de publicaciones, hasta tal punto que muchas de ellas han tenido que profesionalizarse para poder sobrevivir.

Entre toda esa complejidad, un fenómeno destaca por encima de todos: la búsqueda constante de una mejora de la calidad de estas revistas científicas, medida bajo una pretendida objetividad y traducida en criterios casi exclusivamente cuantificables y cuya pertinencia ha sido cuestionada por no pocas voces. Sea como fuere, ese fenómeno ha

\footnotetext{
* Universidad Autónoma de Madrid (España).

*** Universidad Nacional de Educación a Distancia (España).
} 
impulsado en las revistas de literatura académica y científica una evolución notable en sus formatos, en sus maneras de gestión, en sus medios para visibilizarse, etc.

También la $R E E C$, como no podía ser de otra manera, se ha ido adaptando a lo largo de estos 20 años, y en los 25 números que hasta ahora ha publicado, para mantenerse siempre en la mejor posición posible en su ámbito específico de penetración, que viene definido por tres ejes: la Educación Comparada e Internacional como área de especialización; la SEEC y España como espacio geográfico de inmediato impacto; y Europa, Iberoamérica y la amplia realidad mundial como referentes supranacionales inexcusables desde la pertenencia de los miembros de la SEEC y de nuestra Sociedad a la Comparative Education Society of Europe (CESE) y al World Council of Comparative Education Society (WCCES).

Esa evolución adaptativa puede sintetizarse en una serie de hitos clave de enorme relevancia. La REEC comenzó siendo una revista que se publicaba con una periodicidad de un número al año, exclusivamente en edición impresa y que sólo admitía artículos en castellano. Corría el año 1995.

Los inicios del siglo XXI marcan una época de constantes cambios en la REEC. Siete años después de su primer número, la revista introduce, en 2002, su primera innovación. En la sección de Estudios e Investigaciones del $\mathrm{n}^{\circ} 8$ aparece un artículo publicado en lengua inglesa. Desde entonces, ha sido habitual la aparición de escritos en esa lengua, de presencia creciente, como también en francés. Y sólo un año después, a partir del $n^{\circ} 9$, correspondiente al año 2003, se pone ya en marcha un sistema de valoración de artículos mediante el sistema de "pares ciegos", ineludible hoy para cualquier revista que quiera superar controles mínimos de calidad según los criterios de los principales organismos evaluadores... Es también en esas fechas cuando la REEC inicia su versión digital y su visibilidad externa se multiplica, al abrigo de la creación de la página web de la SEEC, en el período de trabajo de la Junta Directiva de 2002-2006, presidida por nuestro recordado profesor Ferran Ferrer y en la que el profesor Luis María Naya tuvo un destacado protagonismo como Secretario y gestor de dicha página web.

El número 15, de 2009, supone un antes y un después en el devenir editorial de la REEC. Al margen de cambios formales para adaptarse a nuevos criterios de calidad, el Consejo Asesor, tal y como se venía denominando hasta entonces, fue sustituido por un Consejo Editorial (compuesto por un reducido número de expertos españoles y con tareas más ejecutivas) y por un Consejo Asesor Internacional, con expertos de los cinco continentes y un papel consultivo de enorme valor para la mejora de los contenidos de la $R E E C$. Desde ese número se hace público también el Comité Evaluador Externo. 
Posteriormente, se decidió editar un número cada semestre. Fue a partir del año 2011, con los números 17 y 18.

El último gran paso evolutivo de nuestra revista tuvo lugar en 2013. Ese año se decidió que la edición sería sólo digital y el número 21 fue el último que se editó en papel...

Ahora, la $R E E C$, con sus 20 años ya de trayectoria, cierra un ciclo y abre otro nuevo, dando un paso más e impulsando un nuevo futuro, decidida a seguir mejorando y a alcanzar la posición de excelencia que merece entre las revistas científicas de su ámbito: a partir del próximo número, toda la gestión editorial de la revista se hará mediante una plataforma OJS, tratando de alcanzar dos objetivos inmediatos y apremiantes para el equipo editorial de la REEC; por un lado, la obtención del sello de calidad de la FECYT; por otro, el paso de la categoría Nacional a Internacional en la base de datos ERIH.

Estamos convencidos que esta decisión, tomada en el marco de los proyectos de la nueva Junta Directiva de la SEEC, que desde noviembre de 2014 preside la profesora Inmaculada Egido, redundará no sólo en la mayor facilidad para llevar a cabo los procesos internos que exige la edición de la REEC sino que permitirá un seguimiento más eficiente a todos los participantes de la revista (autores, evaluadores, coordinadores de la sección monográfica...).

Javier M. Valle (GIPES-UAM) y MJosé García Ruiz (UNED)

Co-Directores de la REEC. 